\title{
Impact of Technological Parameters of CO2 Laser Cutting on oxide adhesion forces on the Base Material
}

\author{
Andrej Zrak ${ }^{1}$, Szymon Tofil ${ }^{2}$, Jozef Šutka ${ }^{1}$, Ján Moravec ${ }^{1}$ \\ ${ }^{1}$ Faculty of Mechanical Engineering, Department of Technological Engineering, University of Žilina, Univerzitná \\ 8215/1010 26 Žilina, Slovakia. E-mail: andrejzrak@gmail.com, jozef.sutka@fstroj.uniza.sk, jan.mora- \\ vec@fstroj.uniza.sk \\ ${ }^{2}$ Faculty of mechatronics and mechanical engineering, Kielce university of technology, Aleja Tysiąclecia Państwa Pol- \\ skiego 7, 25-314 Kielce, Poland. E-mail: tofil@tu.kielce.pl
}

The setting of laser cutting technology parameters affects the resulting state of the final surface. When cutting lowcarbon steel using conventional parameters - oxidative cutting, surface oxide layers are formed on the cutting edges resulting from an exothermic reaction by burning material. The oxide layers are undesirable and can cause complications if the components so produced are further coated. The color coat creates an adhesion layer on the surface oxide, and when the oxide has low adhesion to the base material, the paint drops out of the surface with the oxide. Mechanical removal of oxide by grinding, punching or brushing is another manufacturing operation that causes an increase in the cost of production. Chemical cleaning is, in turn, detrimental to workers and is also a burden on the environment. For chemical purification of oxides, phosphoric acid and the like are used. The paper describes cutting low-grade steels in a way that does not require removal of oxides and adhesion bonding between the component and the color coating is sufficient for the use of the component in operation.

Keywords: Laser cutting, quality of cutting surface, surface oxide, adhesive forces, color coatings.

\section{Introduction}

Laser cutting is a method of energy-efficient thermal separation of materials by the action of photon energy in the presence of an assist gas, which further affects the process that occurs during laser cutting. Largely, the cutting is performed with a laser beam with a power greater than $3000 \mathrm{~W}$ focused in a circle with a diameter of $0.2 \mathrm{~mm}$ or less. From the above can be said, laser cutting is performed through a beam with high area density energy potential. When using such high power, a lot of energy is supplied during each second of the beam to the material, which implies that the setting of the correct technological parameters to ensure the required cutting quality is very sensitive to the values of the parameters, which is stated in almost every scientific article focused on laser processing. The cutting process and the quality of the resulting cutting surface also greatly affects the type of assisting gas that is blown into the cutting area. When oxygen is used, a chemical reaction takes place in the material of a certain chemical composition, which releases additional heat to the environment. When the inert atmosphere is used, the exothermic reaction is prevented and the material is separated by melting the liquid metal. These two basic cutting methods differ from each other by the amount of energy consumed, by the presence of oxides and by the degree of thermal changes in the cut material. This paper describes the effect of setting the individual $\mathrm{CO}_{2}$ laser cutting technology parameters on the selected properties of cutting surfaces and to compare the bonding of surface iron oxides to the base material.

\section{CO2 laser cutting}

Laser cutting is a material separation technology in which the kinetic energy of the photons is transferred to the thermal energy. The rapidly heated materiál melts. The assistance gas is blown through the nozzle to the cutting area. Various assisting gases are used for laser cutting, and this also causes a different way of removing material from the cut gap.

\section{Depending on the gas used:}

- Oxidationcutting - is carried out using pure oxygen assistance gas. It can be applied to all materials that meet the oxygen-acetylene flame-retardant conditions and hence to materials that are burning in the presence of oxygen and the melting temperature is not higher than the burning temperature. When cutting with oxygen, the cut material is heated by the laser beam. When the cut material reaches the burning temperature, the oxidation reaction occurs. Oxidativecuttingischaracterized by the fact that after application, iron oxides - as burning waste products - are found on the surface of the cut edge. Oxidationcuttingisapplied in practically every type and the permissible thickness of lowcarbon steels. The minimum required oxygen purity is 3.5 .

- Melting Cutting- in contrast to oxidative cutting, the protective atmosphere of the inert gas is used. In technical practice, the most commonly used atmosphere is nitrogen. Unlike oxidative cutting, the material does not oxidize and does not burn when melting. The material contained in the cutting gap is melted by the laser beam and 
by the assist gas blown out of the cutting gap. The characteristic of the melting cut is that the cutting surfaces are free of oxides. In practice, the cutting is most commonly applied to chrome-nickel steels, high-grade steels not meeting oxidative cutting conditions and, exceptionally, to low-carbon steels, with specific requirements for the oxide cleanness of cutting surfaces.

\section{Experimental attenuation measurements}

The material of experimental samples. The experimental material was a $2 \mathrm{~mm}$ thick sheet made of S235 steel, which is currently most widely used for the manufacture of conventional dyeing components.

Tab. 1 Chemical composition of steel S235 [\%]

\begin{tabular}{|c|c|c|c|c|}
\hline C & Mn & P & S & N \\
\hline Max. 0.17 & Max. 0.14 & Max. 0.045 & Max. 0.045 & Max. 0.009 \\
\hline
\end{tabular}

\section{Description of a solved problem}

Thereasonwhytheexperimentalwork was done is that in the parts produced by laser cutting and coated by painting, the color layer is often dropped (Figure 1) by the dynamic loading of the paint on the cutting surface. This paint loss occurs because the oxide layers (Figure 2) remain on the surface of the cutting surface when cutting using oxygen assistance gas (conventionally used for cutting this type of material) (Figure 2). This oxide layer has a relatively low adhesion bond to the base material and, if it is the color is applied, the color drop off with the oxide layer.

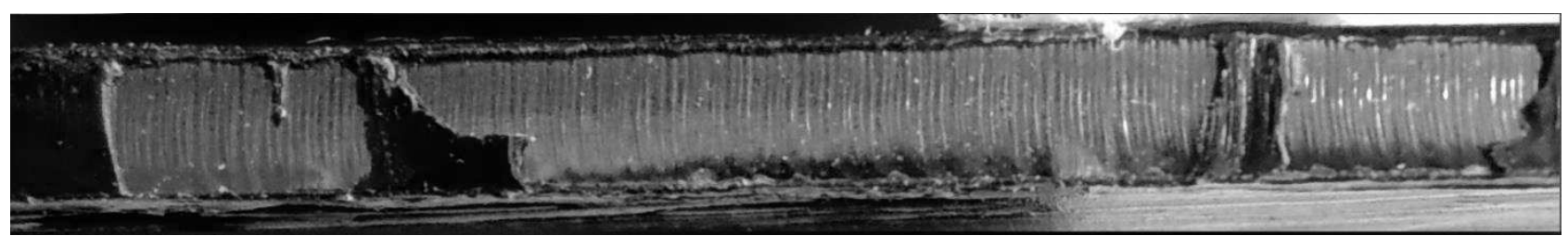

Fig. 1 Picture of the waste paint (black - painted surface, steel silver-area without paint)

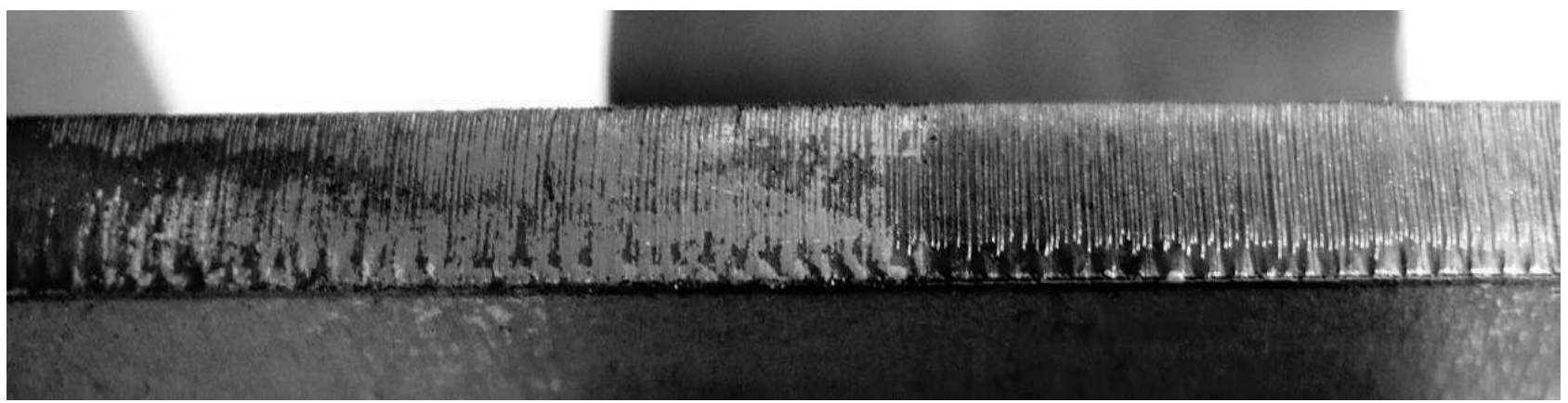

Fig. 2 Surface layer of iron oxide after laser cutting (dark gray-area with oxide layers)

\section{Solution and verification of the accuracy}

To prevent the removal of color coatings from the parts, the companies remove the oxide layers from cutting surfaces. Removal takes place either mechanically - by brushing or by chemically dipping in acidic solutions, causing the oxygen to bind in oxide and decompose the oxide layer. Both ways are an unnecessary burden on the environment and increase production costs. The proposed solution was to use technological parameters in which the oxides on the surface either do not develop or oxides of which the adhesion bond will be large enough to avoid simple separation from the base material. Experimental samples were prepared by different production methods:

1. Cutting using nitrogen assistance gas (Figure 3).

This cutting process prevents the formation of surface oxides during cutting since cutting takes place in an inert atmosphere. However, it is an atypical method of cutting structural steel and is energy and financially more demanding. When comparing the color bonding to the base material in these samples with the oxygen cut samples, the results were very similar. For this reason, this production method was rejected.

2. Cutting using oxygen and mechanical removal of oxides

3. Cutting with oxygen and oxides left on the surface (Figure 4)

4. Cutting using atmospheric air assistance gas. This method has been designed to compare the adhesion of oxides formed in this process. (Figure 5). 
Tab. 2 Technological cutting parameters of experimetal samples

\begin{tabular}{|c|c|c|c|c|c|c|c|}
\hline No. & $\begin{array}{c}\text { Cutting } \\
\text { speed } \\
{[\mathrm{m} / \mathrm{min}]}\end{array}$ & $\begin{array}{c}\text { Diameter of } \\
\text { the nozzle } \\
{[\mathrm{mm}]}\end{array}$ & $\begin{array}{c}\text { Focal lenght } \\
\text { of the lens } \\
{[\mathrm{mm}]}\end{array}$ & Assistence gas & $\begin{array}{c}\text { Nozzle } \\
\text { distance } \\
{[\mathrm{mm}]}\end{array}$ & $\begin{array}{c}\text { Assistance } \\
\text { gas pressure } \\
{[\mathrm{MPa}]}\end{array}$ & $\begin{array}{c}\text { Power of the } \\
\text { laser beam } \\
{[\mathrm{W}]}\end{array}$ \\
\hline 1. & 6.8 & 1.4 & 150 & Nitrogen 5.0 & 0.70 & 1.50 & 3200 \\
\hline 2. & 5 & 0.8 & 150 & Oxygen 3.5 & 0.70 & 0.30 & 1200 \\
\hline 3. & 5 & 0.8 & 150 & Oxygen 3.5 & 0.70 & 0.30 & 1200 \\
\hline 4. & 7 & 1.7 & 150 & Atmospheric air & 0.70 & 0.40 & 3200 \\
\hline
\end{tabular}

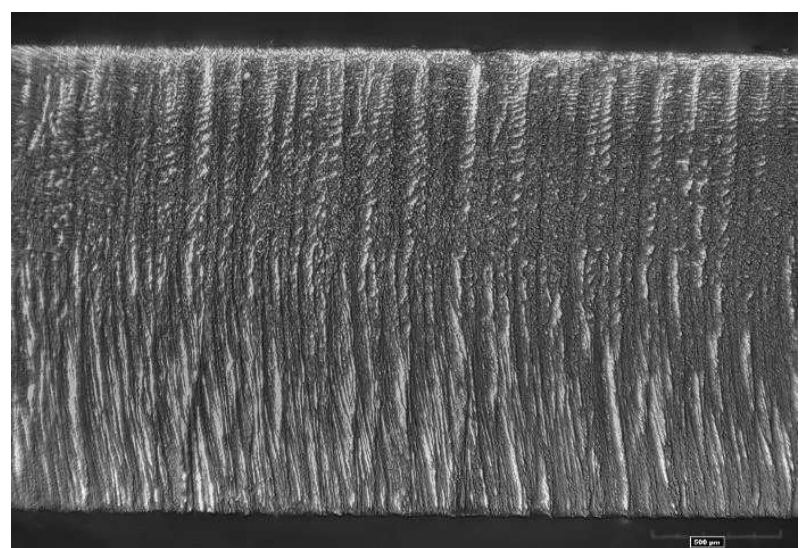

Fig. 3 The cutting surface of steel cut with nitrogen

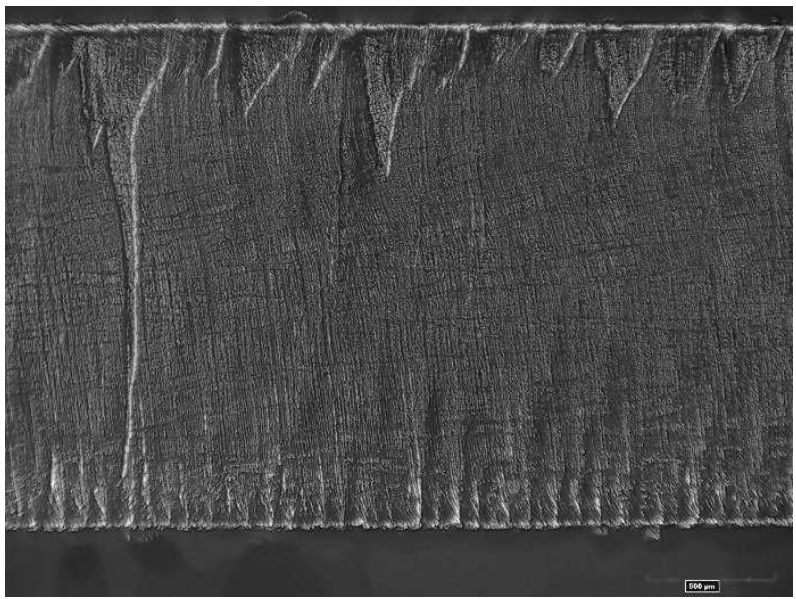

Fig.4 Cutting surface of steel-cut with oxygen

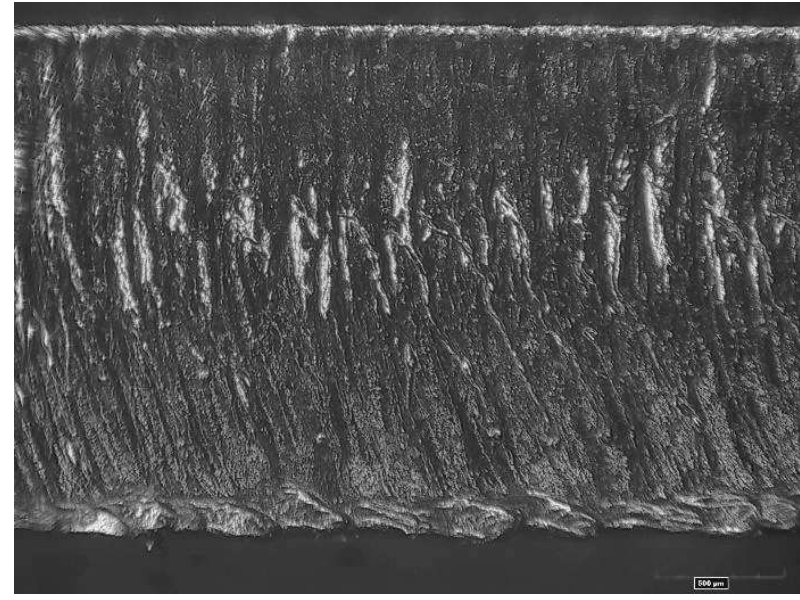

Fig. 5 Cutting surface of steel-cut with atmospheric air

Experimental samples cut out by the three selected methods were painted in powder color.

For the evaluation of color spraying, ISO 2409: 2013 is used in practice. This standard describes a test method for assessing the resistance of paints against separation from base material when the paint is cut from the base material by a rectangular pattern. This standard prescribes the evaluation of coatings up to a thickness of $60 \mu \mathrm{m}$ on the hard base material, cut preparation a distance of cuts $2 \mathrm{~mm}$, $6 \times 6$ cuts perpendicular to one another. This standard does not suit application on the evaluated samples because of the thickness of the sheet - the width of the area to be evaluated is $2 \mathrm{~mm}$.
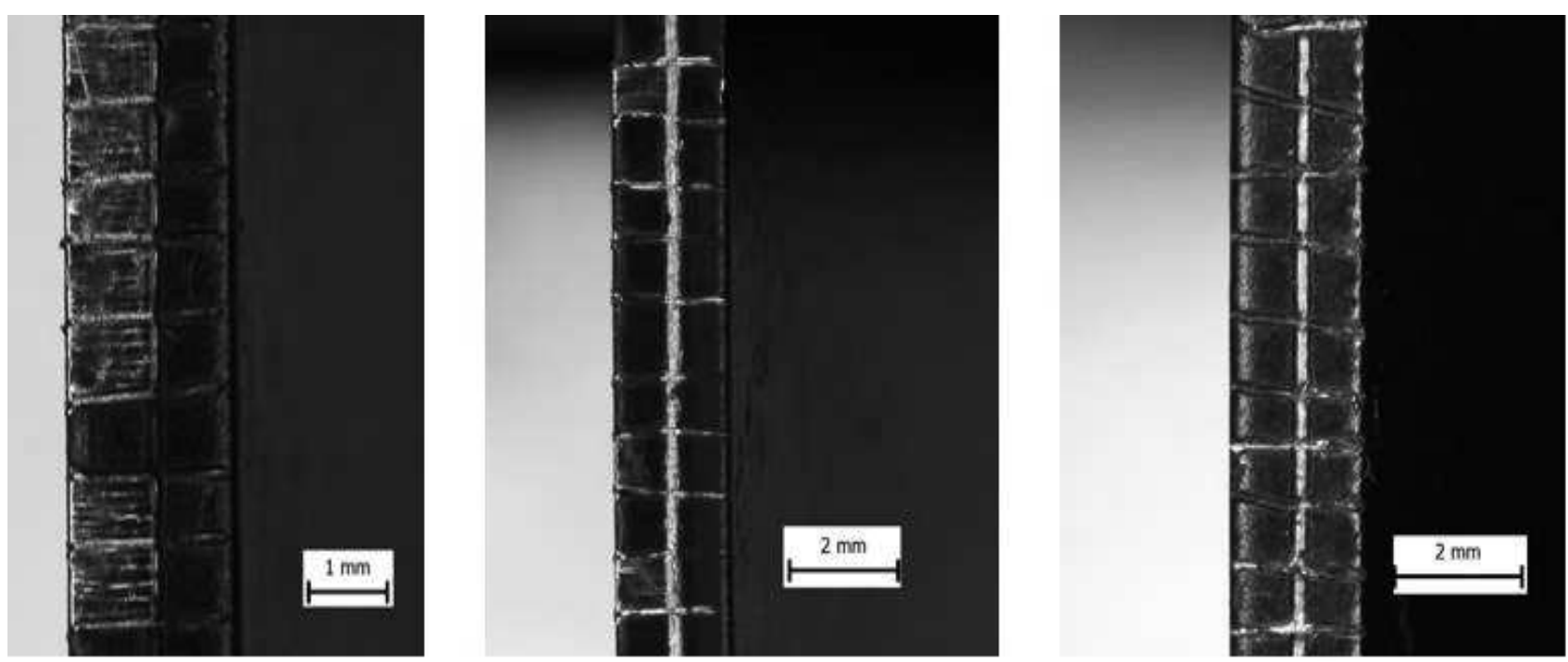

Fig. 6 Grid cut cutting surfaces: left) cutting with oxygen with oxides, middle) cutting with oxygen without oxides, right) cutting with atmospheric air with oxides 


\section{Painting test by grid cut}

Evaluation of the coating resistance to the separation from the base material does not meet the requirements of the standard, but for the comparison of the individual technologies, the cutting of the edge method has been chosen with cuts perpendicular to the edge with a $1 \mathrm{~mm}$ pitch and one cut along the cutting edge in the center. In fig. 6 , it is possible to see the edges of the parts subjected to the grid cut test. On the basis of the test carried out, it can be stated that the coating of the parts cut by oxygen, whether with the removal of oxides or without removal of oxides, does not comply with the prescribed standard. The paint is separated in the whole - loose parts. Sample
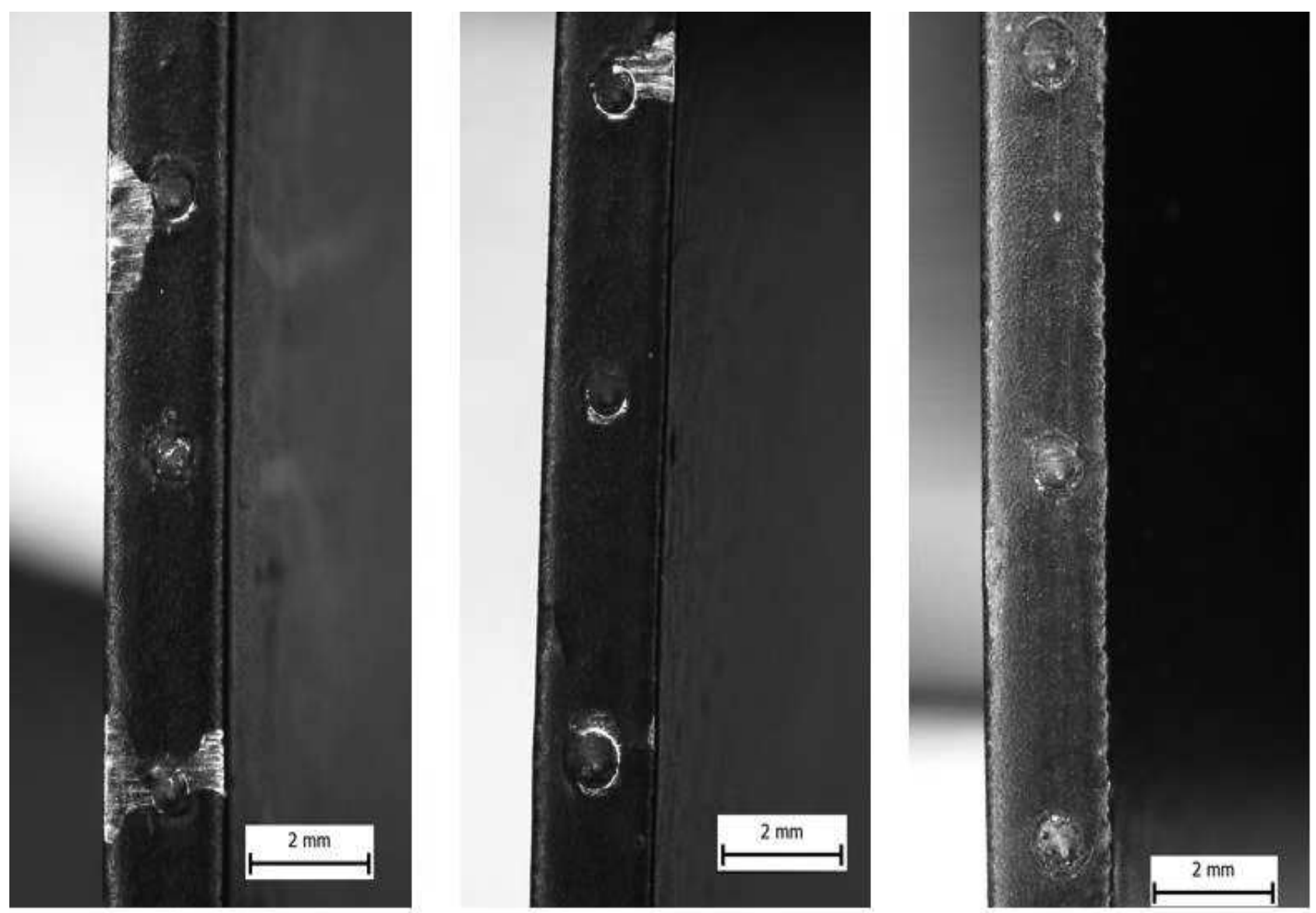

Fig. 7 Cutting surfaces after a dynamic impact test: left) cutting with oxygen, with oxides, middle) cutting with oxygen without oxides, right) cutting with atmospheric air with oxides

On an oxygen-cutting sample, without oxide removal, the color after the impact drops off across all of the material. On the sample, with mechanically removed oxides, the paint drops off near the vicinity of the penetration point into the material. On samples cut with the use of atmospheric air, the color copies the site of the dynamic load, without dropping.

\section{Test for the quantification of adhesive forces in the system coating - the surface of the sample}

As a methodology for quantifying the adhesion of a coating to the surface, a "tensile test" was proposed. The cut in assistant gas - air, conforms to the standard and does not separate from the base material even when applying the adhesive tape according to ISO 2409: 2013.

\section{Dynamic paint test}

The dynamic test designed to analyze the state of the coated edges in the solved problem was designed to consist of a $60^{\circ}$ tip angle diamond tip impact on the coated surface. To carry out the test, a device was produced which delivered kinetic energy of $0.06 \mathrm{~J}$ during the crash. In fig. 7, it is possible to see the shape of the imprints of the tip at the observed edge. 


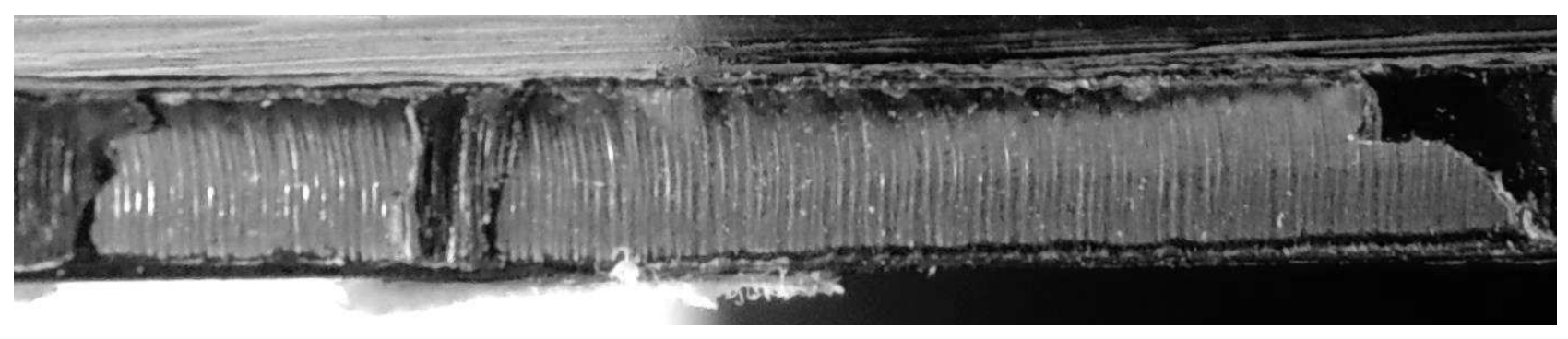

Fig. 8 Tensile test - cutting with oxygen with oxides

Samples from which the oxides were mechanically removed had a minimum separation value of $4.0 \mathrm{kN}$ and a maximum of $4.5 \mathrm{kN}$. The color was completely removed from the cutting surfaces (Figure9).

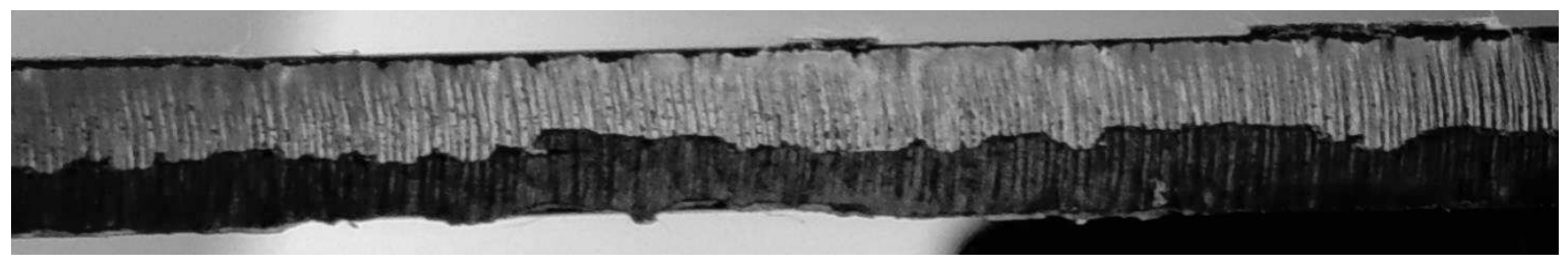

Fig. 9 Tensile test- cutting with oxygen without oxides

For samples that were cut using atmospheric air as an assistant gas, the rupture value was $4.5-5.0 \mathrm{kN}$. However, the color was not separated from the cutting surfaces even after breaking (Figure 10). The strength required for separation, in this case, indicates the strength of the glue that the experimental samples were glued to.

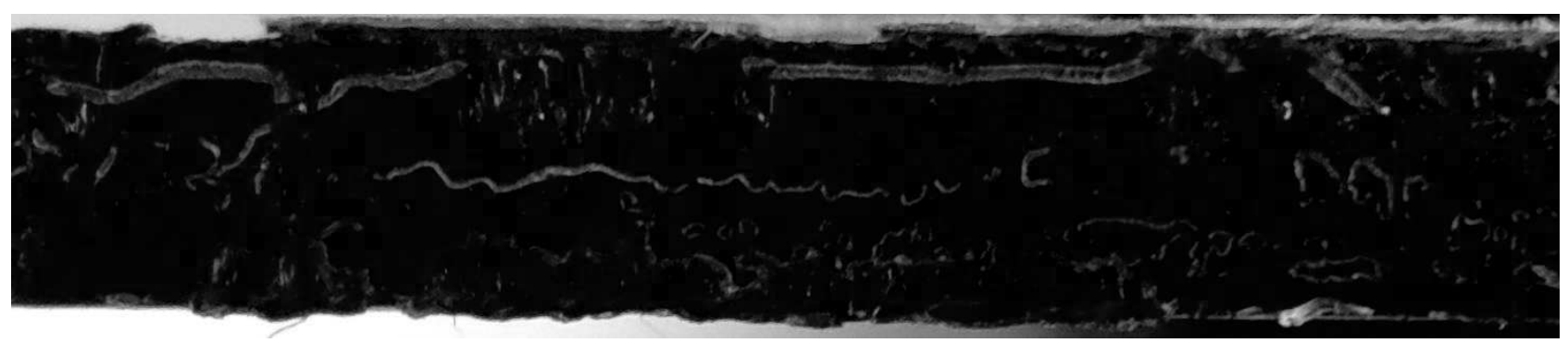

Fig. 10 Tensile test-cutting with atmospheric air with oxides

For a more detailed analysis of the presence of oxides, microscopic observations were performed. The parts that have been observed are taken from the experimental samples by cross-section to see the area where the transition is from the base material to oxide. Based on the analysis of the obtained images, the presence of oxides can be ascertained in both cases. In the oxygen cut samples, the surface has a lower roughness and the thickness of the oxide layer is uniform compared to the air-cut sample. (When preparing a steel cut with oxygen application, careful processing and polishing of the experimental specimen are needed due to the high affinity of oxides for separation from the cutting surface.)

\section{Conclusions}

All experimental measurements and tests performer can bee evaluated as follows. Oxides produced by cutting in the oxygen atmosphere 3.5 have a negative effect on the adhesion of the paint to the basic material. The color adheres to oxide, which can be relatively easy to remove from the basic material. Mechanical removal of oxides will increase the degree of resistance of the paint against separation from the surface, coatings on cutting surfaces in the assisting gas - the air, however, exhibit the greatest resistance to separation from the base material. If the surface of the materiál is free of oxides, as long as the oxides on the surface are formed when being cut by using atmospheric air, the forces required to tear the paint are at least twice as high. The experimental work described in the paper has shown the increase of the adhesion bonding in the system basic material - color, conventional oxygen cutting, and removal of oxide coatings can be applied, or atmospheric air-assisted gas cutting, where the adhesion of color paints is highest and in none of the experiments the colored paint was not separated from the component.

\section{References}

[1] BOLIBRUCHOVÁ, D., BRŮNA, M. (2017) Impact of the elements affecting the negative iron-based phases morphology in aluminium alloys-Summary results. Manufacturing Technology. Vol. 17(5), 675-679, ISSN 1213-2489.

[2] Bolibruchová, D., Richtárech, L., Dobosz, S.M., MAJOR-GABRYS, K. (2017) Utilisation of mould temperature change in eliminating the 
$\mathrm{Al}_{5} \mathrm{FeSi}$ phases in secondary A1Si7M0.3 alloys $\mathrm{Ar}$ chives of Metallury and materials. Volume 62 (1), 339-344 ISSN 1733-3490.

[3] Zrak, A., Mesko, J., Morvec, J., Nigrovic, R. (2016) Contactless thermal bending of steel sheets. In: Manufacturing Technology, Vol. 16, Iss. 1, 2016, p. 309-313, ISSN: 1213-2489

[4] Konar, R., Mician, M., Patek, M., Kadas, D. (2016) Finite element modeling and numerical simulation of welding at the repair of gas pipelines with steel sleeve. In: Manufacturing Technology, Vol. 16, Iss. 2, 2016, p. 360-365, ISSN: 1213-2489

[5] KONAR, R., BOHACIK, M., MICIAN, M. (2016) Defect Identification in Butt Weld Joint by Ultrasonic Method Phased Array and X-Ray Technique. In: Manufacturing Technology, Vol. 16, Iss. 5, 2016, p. 955-961, ISSN: 1213-2489

[6] BOHACIK, M., MICIAN, M., KONAR, R. (2017) Evaluating the attenuation in ultrasonic testing for AlSi alloys castings. In: Manufacturing Technology, Vol. 17, Iss. 5, 2017, p. 669-674, ISSN: 1213-2489

[7] KONAR, R., PATEK, M. (2017) The Evaluation of Wear Mechanism of High-carbon Hardfacing
Layers. In: Technicki vjesnik - Technical Gazette, Vol. 24, Iss. 1, 2017, p.137-142, ISSN 1330-3651

[8] BAKSA, T., FARSKY, J., HRONEK, O., ZETEK, M. (2019) Surface quality after Grinding VACO 180 Tool Steel using Different Cutting Conditions, In: Manufacturing Technology, Vol. 19, Iss. 2, 2019, p. 179-183, ISSN: 1213-2489

[9] OVSIK, M., HYLOVA, L., REZNICEK, M., SENKERIK, V., STANEK, M. (2019) The Influence of Finishing Operations on the Surface Quality of Injected Parts. In: Manufacturing Technology, Vol. 19, Iss. 3, 2019, p. 477-481, ISSN: 1213-2489

[10] BARENYI, I. (2018) Study of Heat Affected Zone after Cutting and Welding of Armoured Ultra-high Strength Steels. In: Manufacturing Technology, Vol. 18, Iss. 2, 2018, p. 185-189, ISSN: 1213-2489

[11] POKORNY, Z., DOBROCKY, D., STUDENY, Z. (2018) Influence of Chemical Composition on Layer Properties of Barrel Steels. In: Manufacturing Technology, Vol. 19, Iss. 3, 2019, p. 1007 1010, ISSN: 1213-2489 